\title{
Caerulein induced plasma amino acid decrease: a simple, sensitive, and specific test of pancreatic function
}

\author{
L Gullo, R Pezzilli, M Ventrucci, L Barbara
}

\begin{abstract}
We measured total plasma amino acid concentrations before and during pancreatic stimulation with secretin (1 clinical unit/kg/h) and caerulein $(50 \mathrm{ng} / \mathrm{kg} / \mathrm{h})$ in 28 healthy volunteers, 60 patients with chronic pancreatitis ( 25 mild to moderate, 35 severe), and 22 patients with non-pancreatic digestive disease. In the healthy volunteers and patients with non-pancreatic digestive disease pancreatic stimulation caused a significant decrease $(p<0.001)$ in plasma amino acid concentration, whereas in patients with chronic pancreatitis the decrease did not occur or was only slight. In six healthy volunteers and 24 patients with chronic pancreatitis (nine mild to moderate, 15 severe) repetition of the test using caerulein alone showed no significant differences from combined stimulation. Using the maximal per cent decrease in plasma amino acid concentration as an index of pancreatic function (lower normal limit 14\%), 20 of the 25 patients with mild to moderate pancreatitis $(80 \%)$ and 32 of the 35 with severe pancreatitis $(91.4 \%)$ had values clearly below normal. The overall sensitivity of the test $(86.7 \%)$ was significantly greater than that of the pancreolauryl test $(64.2 \%)(p<0.02)$ and that of faecal chymotrypsin $(66 \%)(p<0.05)$. None of the patients with non-pancreatic digestive disease had abnormal values. We conclude that the assessment of the decrease in the plasma amino acid concentration during pancreatic stimulation with secretin and caerulein is a simple, sensitive, and highly specific test of pancreatic function. The data obtained using caerulein stimulation alone suggest that the test can be further simplified, and made less costly, by eliminating the use of secretin.
\end{abstract}

Direct tests of pancreatic function, although most sensitive and specific in the diagnosis of exocrine pancreatic insufficiency, ${ }^{1-3}$ are not widely used in clinical practice because they are somewhat complex, time consuming, and unpleasant for patients. For these reasons pancreatologists have been trying to develop simple and tubeless pancreatic function tests which would be more suitable for wide clinical use. Unfortunately, the tubeless tests currently available have a satisfactory sensitivity only in patients with severe pancreatic insufficiency, ${ }^{1-3}$ which limits their clinical use. In a recent paper Domschke $e t a l^{4}$ reported that pancreatic stimulation with secretin and cholecystokinin caused a decrease in plasma amino acid concentration which was significantly correlated to pancreatic enzyme secretion, and they suggested that the determination of this decrease could be a reliable means of assessing pancreatic function. Prompted by these findings to carry out the present study, our aims were: (a) to assess the validity of this new tubeless pancreatic function test in the diagnosis of pancreatic insufficiency; (b) to compare its sensitivity with that of the pancreolauryl test and faecal chymotrypsin, two of the most widely used tubeless pancreatic function tests ${ }^{12}$; (c) to determine whether the test could be further simplified and made less costly by eliminating the use of secretin.

\section{Patients and methods}

A total of 110 volunteers and patients, divided into three groups, were studied after giving written informed consent.

Group 1: control subjects. This group consisted of 28 healthy volunteers who were not alcoholics and had no evidence of digestive disease ( 24 men and four women; average age 40 years, range 1967 years).

Group 2: chronic pancreatitis. This group consisted of 60 patients with chronic pancreatitis (56 men and four women; average age 50 years, range 32-77 years). The pancreatitis was of alcoholic origin in 55 patients and idiopathic in five. The diagnosis of chronic pancreatitis was based on the clinical history (recurrent attacks of upper abdominal pain with hyperamylasaemia) and on the findings of ultrasonography and endoscopic retrograde pancreatography. It was further confirmed by radiological evidence of pancreatic calcification in 37 cases and by surgical and histological findings in seven. From morphological changes found with ultrasonography and ductal changes seen with endoscopic retrograde pancreatography, 25 patients were considered to have mild to moderate chronic pancreatitis and 35 severe pancreatitis. Morphological changes were classified according to an ultrasonographic score which takes into account the size and structure of the gland, the calibre of the Wirsung duct, the presence of fluid collections and calcification, and the calibre of the extrapancreatic bile duct, as described in detail in a previous paper. ${ }^{5}$ Ductal changes were assessed according to the criteria of Kasugai $e$ $a l .{ }^{6}$ In addition, 16 of the 25 patients with mild to moderate pancreatitis and 22 of the 35 patients with severe pancreatitis had a faecal fat estimation which showed that none of the 16 had steatorrhoea whereas all 22 with severe pancreatitis had steatorrhoea (faecal fat excretion $>6$ $\mathrm{g} / 24 \mathrm{~h}$ ). All patients were studied during a stable pain free period. During the week before the 


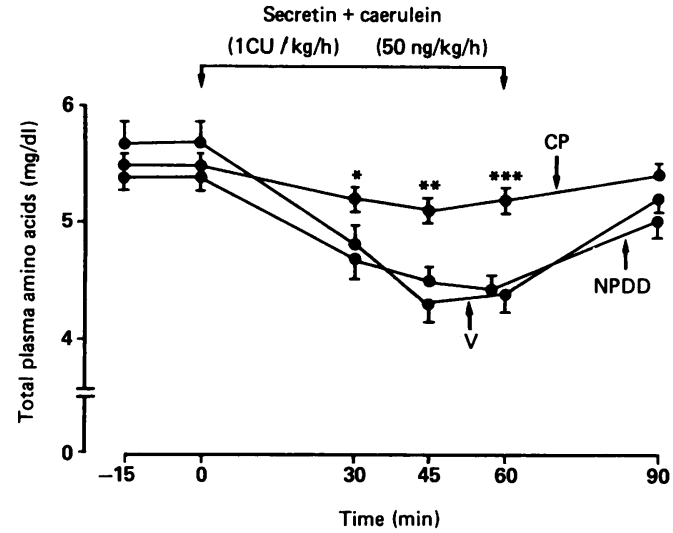

Figure 1: Total plasma amino acid concentration before, during, and after pancreatic stimulation with secretin (clinica unit/kg) and caerulein (ng/kg) in 28 healthy volunteers $(V), 60$ patients with chronic pancreatitis $(C P)$, and 22 patients with non-pancreatic digestive disease (NPDD). Means $(S E M)$. ${ }^{\star} p<0 \cdot 02,{ }^{\star}{ }^{\prime} p<0.002,{ }^{\star \star \star} p<0.001$, in comparison with $V$ and NPDD.

study patients who were taking pancreatic extracts discontinued treatment.

Group 3: non-pancreatic digestive disease. This group consisted of 22 patients ( 17 men and five women; average age 47 years, range 17-74 years) suffering from various digestive diseases: six cirrhosis of the liver; three cholelithiasis; three postcholecystectomy syndrome; two active duodenal ulcer; three had diarrhoea, due to Crohn's disease in two and lactase deficiency in one; two had steatorrhoea due to coeliac disease; one oesophagitis; one Billroth II gastrectomy; and one intestinal pseudo-obstruction.

Studies were performed in the morning after an overnight fast. Each of the 110 subjects received a continuous one hour intravenous infusion of synthetic secretin ( 1 clinical unit $/ \mathrm{kg} / \mathrm{h}$ ) (Sekretolin, Hoechst AG, Frankfurt am Main, FRG) and caerulein (50 ng/kg/h) (Takus, Farmitalia, Milan, Italy) dissolved in $0.9 \% \mathrm{NaCl}$ solution. During each study blood samples for amino acid determination were taken before the infusion was started at -15 and 0 min; during the infusion at 30,45 , and $60 \mathrm{~min}$; and $30 \mathrm{~min}$ after the infusion was stopped.

In six healthy volunteers and 24 patients with chronic pancreatitis (nine mild to moderate, 15 severe) the test was repeated on a separate day (10-15 days after the first test) by stimulating the pancreas with a one-hour intravenous infusion of caerulein alone $(50 \mathrm{ng} / \mathrm{kg} / \mathrm{h})$.

Total plasma amino acids were estimated photometrically using the colorimetric method

TABLE I Total plasma amino acid concentration ( $m g / d l)$ before, during, and after pancreatic stimulation with secretin $(S)$ and caerulein $(C)$ or caerulein alone in six healthy volunteers and 24 patients with chronic pancreatitis (nine mild to moderate, 15 severe)

\begin{tabular}{|c|c|c|c|c|c|c|}
\hline & \multirow[b]{2}{*}{$-15 \min$} & \multicolumn{4}{|l|}{$S+C$ or $C$} & \multirow[b]{2}{*}{$90 \min$} \\
\hline & & $0 \min$ & $30 \min$ & $45 \min$ & $60 \mathrm{~min}$ & \\
\hline $\begin{array}{l}\text { Volunteers } \\
\text { S+C } \\
\text { C }\end{array}$ & $\begin{array}{l}5 \cdot 8(0 \cdot 2) \\
5 \cdot 7(0 \cdot 3)\end{array}$ & $\begin{array}{l}5 \cdot 8(0 \cdot 2) \\
5 \cdot 7(0.3)\end{array}$ & $\begin{array}{l}5 \cdot 1(0 \cdot 2) \\
5 \cdot 1(0 \cdot 3)\end{array}$ & $\begin{array}{l}4.5(0.2) \\
4.5(0.4)\end{array}$ & $\begin{array}{l}4.6(0.3) \\
4.5(0.4)\end{array}$ & $\begin{array}{l}5.4(0.2) \\
5.4(0.2)\end{array}$ \\
\hline $\begin{array}{l}\text { pancreatitis } \\
\text { S+C } \\
C\end{array}$ & $\begin{array}{l}5.5(0.2) \\
5.5(0.1)\end{array}$ & $\begin{array}{l}5.5(0.2) \\
5.5(0.1)\end{array}$ & $\begin{array}{l}5 \cdot 2(0 \cdot 2) \\
5 \cdot 3(0 \cdot 2)\end{array}$ & $\begin{array}{l}5 \cdot 1(0 \cdot 2) \\
5 \cdot 1(0 \cdot 2)\end{array}$ & $\begin{array}{l}5 \cdot 2(0 \cdot 2) \\
5 \cdot 1(0 \cdot 2)\end{array}$ & $\begin{array}{l}5.4(0.2) \\
5.4(0.1)\end{array}$ \\
\hline
\end{tabular}

$\mathrm{S}+\mathrm{C}=\sec$ etin $(1$ clinical unit $/ \mathrm{kg} / \mathrm{h})$ plus caerulein $(50 \mathrm{ng} / \mathrm{kg} / \mathrm{h})$.

$\mathrm{C}=$ caerulein $(50 \mathrm{ng} / \mathrm{kg} / \mathrm{h})$

Values are mean (SEM). described by Frame et al..$^{7}$ Recovery of exogenous amino acids after plasma deproteinisation was greater than $95 \%$. Intra-assay and interassay variations (20 determinations) were $2 \cdot 6 \%$ and $9 \cdot 2 \%$, respectively.

In addition, patients with chronic pancreatitis underwent the pancreolauryl test, using the method previously described in our laboratory, ${ }^{8}$ and faecal chymotrypsin determination, using a colorimetric method commercially available as a kit (Monotest Chymotrypsin, Boehringer Mannheim Diagnostica, FRG).

Statistical evaluation of the data was carried out using the Wilcoxon matched pairs signed rank test, Wilcoxon rank sum $W$ test, and McNemar test. The results are expressed as mean (SEM).

\section{Results}

The basal plasma amino acid concentrations of the three groups of subjects did not differ significantly (Fig 1). In healthy volunteers and in patients with non-pancreatic digestive disease pancreatic stimulation with secretin and caerulein caused a significant decrease $(p<0.001)$ in plasma amino acid concentration: the average per cent reductions (mean (SEM)) were 16.0 $(1 \cdot 5), 23 \cdot 8(2 \cdot 4)$, and $22 \cdot 2(2 \cdot 3)$ in the former and $13 \cdot 0(1 \cdot 7), 17 \cdot 1 \cdot 1 \cdot 3)$, and $20 \cdot 1(1 \cdot 5)$ in the latter at 30,45 , and $60 \mathrm{~min}$ during pancreatic stimulation. After the infusion stopped plasma amino acids tended to return towards basal values. In patients with chronic pancreatitis pancreatic stimulation with secretin and caerulein caused no decrease or only a slight decrease in plasma amino acids (Fig 1). The average per cent decrease (mean (SEM)) was 5.0 (1.0), $6.5(1 \cdot 0)$, and $6 \cdot 2(1.0)$ at 30,45 , and $60 \mathrm{~min}$ during stimulation. The differences between the chronic pancreatitis group and the two other groups were significant (Fig 1).

Table I gives the plasma amino acid concentrations (mean (SEM)) during combined stimulation with secretin and caerulein and caerulein stimulation alone in six healthy volunteers and 24 patients with chronic pancreatitis. No significant differences were observed between these two methods of stimulation.

Figure 2 shows the individual values of the maximal per cent decrease in plasma amino acid concentrations during secretin and caerulein stimulation in the three groups. In almost all cases the maximal decrease occurred at 45 or 60 min of stimulation. Only in three volunteers and four chronic pancreatitis patients did it occur at $30 \mathrm{~min}$. Using the 97.5 percentile, the lower normal limit was $14 \cdot 4 \%$ which has been arbitrarily rounded off to $14 \%$. Fifty two of the 60 patients with chronic pancreatitis (20 mild to moderate, 32 severe) had values below the normal limit. All patients with non-pancreatic digestive disease had values above this limit.

Table II summarises the diagnostic sensitivity of the amino acid test-that is, the maximal plasma amino acid decrease during secretin and caerulein stimulation-the pancreolauryl test, and the faecal chymotrypsin estimation in patients with chronic pancreatitis. In mild to moderate chronic pancreatitis the sensitivity of 
Figure 2: Individual values of the maximal per cent decrease in plasma amino acid concentration during pancreatic stimulation with secretin and caerulein. $V=$ healthy volunteers $C P=$ chronic pancreatitis, mild to moderate $(\mathrm{O})$ and severe $(O) ; N P D D=$ nonpancreatic digestive disease. The broken horizontal line represents the lower norma limit. $N S=$ not significant.

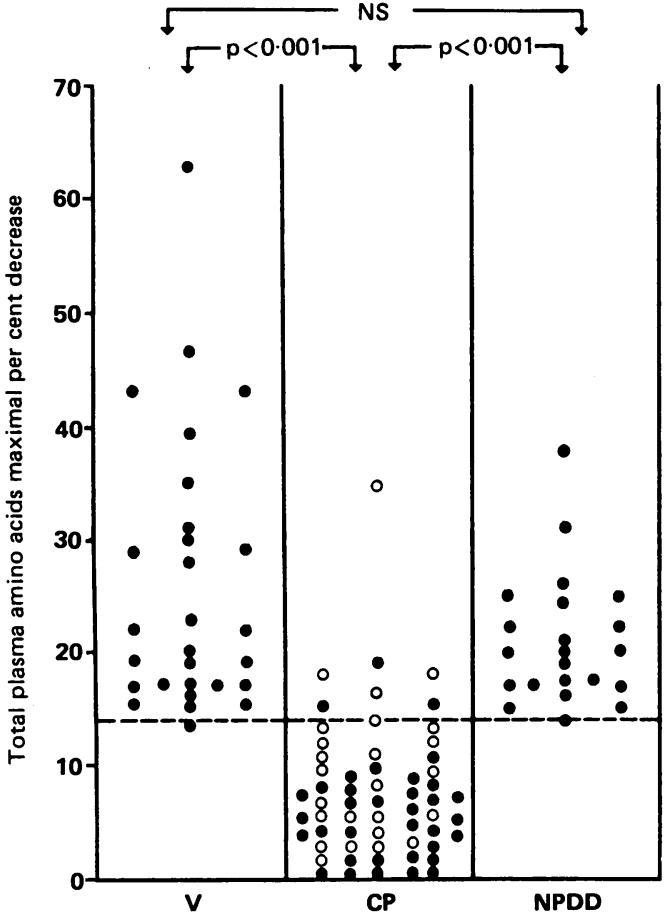

the amino acid test was significantly greater than that of the two other tests $(\mathrm{p}<0.02$ and $\mathrm{p}<0.05$, respectively), whereas in severe pancreatitis the sensitivity was slightly but not significantly higher. The overall sensitivity of the amino acid test was also significantly greater than that of the pancreolauryl test $(p<0.02)$ and faecal chymotrypsin $(\mathrm{p}<0 \cdot 05)$.

\section{Discussion}

The results of this study show that pancreatic stimulation with secretin and caerulein causes a significant decrease in plasma amino acid concentration in healthy subjects and that this does not occur or is only slight in patients with chronic pancreatitis. The results are in agreement with those of Domschke $e t a l^{4}$ who, using comparable doses of secretin and cholecystokinin, found similar effects on plasma amino acid concentrations. In addition, our data show that pancreatic stimulation with caerulein alone causes decreases in plasma amino acid concentrations almost identical to those caused by a combination of secretin and caerulein, indicating that, at the peptide doses used in this study, the effect on amino acid concentrations can be attributed exclusively to caerulein.

TABLE II Sensitivity of the amino acid test (maximal plasma amino acid decrease during secretin and caerulein stimulation), the pancreolauryl test, and faecal chymotrypsin estimation in chronic pancreatitis

\begin{tabular}{|c|c|c|c|}
\hline & \multicolumn{2}{|c|}{ Chronic pancreatitis } & \multirow[b]{2}{*}{$\begin{array}{l}\text { Total } \\
(n=60)\end{array}$} \\
\hline & $\begin{array}{l}\text { Mild-moderate } \\
(n=25)\end{array}$ & $\begin{array}{l}\text { Severe } \\
(n=35)\end{array}$ & \\
\hline $\begin{array}{l}\text { Amino acid test }(\%) \\
\text { Pancreolauryl test }(\%)^{\star} \\
\text { Faecal chymotrypsin }(\%)^{\star}\end{array}$ & $\begin{array}{l}80 \cdot 0 \dagger \\
41 \cdot 7 \\
48 \cdot 0\end{array}$ & $\begin{array}{l}91 \cdot 4 \\
82 \cdot 8 \\
82 \cdot 1\end{array}$ & $\begin{array}{l}86 \cdot 7 \dagger \\
64 \cdot 2 \\
66 \cdot 0\end{array}$ \\
\hline
\end{tabular}

One of the objectives of this study was to determine the sensitivity of this new test of pancreatic function in the diagnosis of pancreatic insufficiency in a large series of patients with chronic pancreatitis and to compare its sensitivity with that of the pancreolauryl and the faecal chymotrypsin tests. Using the maximal per cent decrease in plasma amino acid concentration as an index of pancreatic function, we found that most of the patients with chronic pancreatitis (52/60) had subnormal decreases in plasma amino acid concentrations. This sensitivity $(\mathbf{8 6 . 7 \% )})$ is slightly lower than that found by Domschke et $a l^{4}(91 \%)$ in their study of 30 patients with chronic pancreatitis. It is, however, satisfactory, given that about half of the patients had mild to moderate chronic pancreatitis as shown by ultrasonographic and pancreatographic findings and by the absence of steatorrhoea.

Compared with the pancreolauryl test and faecal chymotrypsin the sensitivity of the amino acid test was significantly greater. This was especially true for patients with mild to moderate chronic pancreatitis in whom the sensitivity of the amino acid test was $80 \%$ against $41 \cdot 7 \%$ and $48 \%$ for the other two tests (see Table II). Since the sensitivity of the Paba-test (another of the tubeless pancreatic function tests in wide use) is similar to or even lower than that of the pancreolauryl test ${ }^{128}$ it is likely that the same can be stated for the Paba-test.

To assess the specificity of the amino acid test we studied a group of patients affected by various non-pancreatic digestive diseases, including some with intestinal malabsorption. None of these patients had abnormal values, indicating that the test is highly specific. This might be related to the fact that the amino acid test involves a direct stimulation of the pancreas, and so it is not affected by extrapancreatic factors. This would be a major advantage over the tubeless tests currently used in the clinic which have a limited specificity. ${ }^{8-13}$

As for the pancreatic stimulants, the results obtained in healthy volunteers and in chronic pancreatitis patients in whom the test was repeated using caerulein alone indicate that the use of secretin is not necessary, so the elimination of this peptide can further simplify the test and render it less costly. We used caerulein instead of cholecystokinin becaue it is a synthetic preparation, free of impurities, and it is less costly and more easily obtainable (at least in Italy) than cholecystokinin. The dose we used is probably near maximal ${ }^{14}$; however, further studies are now in progress to establish the optimal dose of this peptide.

The blood sample taken for amino acid determination 30 minutes after pancreatic stimulation had no diagnostic value and can, therefore, be omitted. In addition, since the two basal amino acid concentrations (at -15 and 0 minutes before hormonal infusion) were almost identical in all cases, the blood sample at -15 minutes could also be omitted, which further reduces the duration of the test.

Domschke et $a l^{4}$ reported that the measurement of some amino acids such as serine, valine, isoleucine, histidine, and lysine could help to 
assess pancreatic insufficiency better than the total amino acid concentration. Since the determination of individual plasma amino acids is a complex and time consuming procedure, however, and feasible only in specialised laboratories, it cannot be proposed for clinical use at present.

In conclusion, our study indicates that (a) the assessment of the decrease in the total plasma amino acid concentration during pancreatic stimulation with secretin and caerulein is a simple, sensitive, and highly specific test of pancreatic function; (b) its sensitivity is significantly greater than that of the other tubeless tests currently available; (c) the use of secretin is very likely superfluous and can be eliminated.

We thank Dr W Groppi (Farmitalia, Milan, Italy) for his generosity in supplying us with caerulein

1 Lankisch PG. Exocrine pancreatic function tests. Gut 1982;

2 23: 777-98. Gastroenterology 1985; 88: 1973-95.

3 Gullo L. Pancreatic function test by means of duodenal intubation. In: Malfertheiner P, Ditschuneit H, eds. Diagnostic procedures in pancreatic disease. Berlin: Springer Verlag, 1986: 201-7.

4 Domschke S, Heptner G, Kolb S, Sailer D, Schneider MU,
Domschke W. Decrease in plasma amino acid level after secretin and pancreozymin as an indicator of exocrine pancreatic function. Gastroenterology 1986; 90: 1031-8.

5 Bolondi L, Priori P, Gullo L, et al. Relationship between morphological changes detected by ultrasonography and pancreatic exocrine function in chronic pancreatitis Pancreas 1987; 2: 222-9.

6 Kasugai T, Kuno N, Kizu M, Kobayashi S, Hattori K. Endoscopic pancreatocholangiography. II. The pathologica endoscopic pancreatocholangiogram. Gastroenterology 1972; 63: $227-34$.

7 Frame EG, Russel JA, Wilhelmi AE. The colorimetric estimation of amino nitrogen in blood. $\mathcal{F}$ Biol Chem 1943; 149: 255-70.

8 Ventrucci M, Gullo L, Daniele C, Priori P, Labò G. Pancreolauryl test for pancreatic exocrine insufficiency. $A m$ creolauryl test for pancreatic

9 Kay G, Hine P, Braganza J. The pancreolauryl test. A method of assessing the combined functional efficacy of pancreatic esterase and bile salts in vitro? Digestion 1982; 24:241-5.

10 Boyd EJS, Cumming JGR, Cuschieri A, Wood RAB, Wormsley KG. Prospective comparison of the fluorescein-dilaurate test with the secretin-cholecystokinin test for pancreatic exocrine function. $\mathcal{F}$ Clin Pathol 1982; 35: 1240-3.

11 Lankisch PG, Schreiber A, Otto J. Pancreolauryl test. Evaluation of a tubeless pancreatic function test in comparison with other indirect and direct tests of exocrine pancreatic function. Dig Dis Sci 1983; 28: 490-3.

12 Malfertheiner P, Peter M, Junge U, Ditschuneit H. Der orale pankreasfunktiontest mit FDL in der diagnose der chronischen pankreatitis. Klin Wochenschr 1983; 61: 193-8

13 Ventrucci $M$, Gullo L, Daniele $C$, et al. Evaluation of BT PABA test in the diagnosis of pancreatic exocrine insuffiPABA test in the diagnosis of pancreatic

14 Ribet A, Tournut R, Duffaut M, Vaysse N. Use of caerulein with submaximal doses of secretin as a test of pancreatic function in man. Gut 1976; 17: 431-4. 